\title{
Recurrent Oral Cavity Adenoid Cystic
} Carcinoma

National Cancer Institute

\section{Source}

National Cancer Institute. Recurrent Oral Cavity Adenoid Cystic Carcinoma. NCI

Thesaurus. Code C8216.

The reemergence of adenoid cystic carcinoma in the oral cavity after a period of remission. 